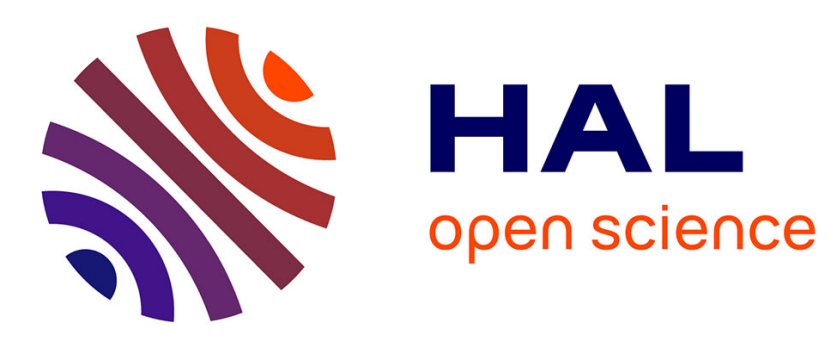

\title{
An Experiment on Lowest Unique Integer Games
}

Takashi Yamada, Nobuyuki Hanaki

\section{To cite this version:}

Takashi Yamada, Nobuyuki Hanaki. An Experiment on Lowest Unique Integer Games . Physica A: Statistical Mechanics and its Applications, 2016, 463, pp.88-102. 10.1016/j.physa.2016.06.108 . halshs-01204814v2

\section{HAL Id: halshs-01204814 \\ https://shs.hal.science/halshs-01204814v2}

Submitted on 15 Jun 2016

HAL is a multi-disciplinary open access archive for the deposit and dissemination of scientific research documents, whether they are published or not. The documents may come from teaching and research institutions in France or abroad, or from public or private research centers.
L'archive ouverte pluridisciplinaire HAL, est destinée au dépôt et à la diffusion de documents scientifiques de niveau recherche, publiés ou non, émanant des établissements d'enseignement et de recherche français ou étrangers, des laboratoires publics ou privés. 


\title{
An Experiment on Lowest Unique Integer Games*
}

\author{
Takashi Yamada ${ }^{\dagger}$ and Nobuyuki Hanaki ${ }^{\ddagger}$
}

\begin{abstract}
We experimentally study Lowest Unique Integer Games (LUIGs) to determine if and how subjects self-organize into different behavioral classes. In a LUIG, $N(\geq 3)$ players submit a positive integer up to $M$ and the player choosing the smallest number not chosen by anyone else wins. LUIGs are simplified versions of real systems such as Lowest/Highest Unique Bid Auctions that have been attracting attention from scholars, yet experimental studies are scarce. Furthermore, LUIGs offer insights into choice patterns that can shed light on the alleviation of congestion problems. Here, we consider four LUIGs with $N=\{3,4\}$ and $M=\{3,4\}$. We find that (a) choices made by more than $1 / 3$ of subjects were not significantly different from what a symmetric mixed-strategy Nash equilibrium (MSE) predicts; however, (b) subjects who behaved significantly differently from what the MSE predicts won the game more frequently. What distinguishes subjects was their tendencies to change their choices following losses.
\end{abstract}

Keywords: Lowest Unique Integer Game, Laboratory Experiment

\section{Introduction}

We ran laboratory experiments to study the manner in which subjects play Lowest Unique Integer Games (LUIGs) and if and how they self-select themselves into different behavioral groups.

In a LUIG, $N(\geq 3)$ players simultaneously submit a positive integer up to $M$. The player choosing the smallest number that is not chosen by anyone else is the winner. In cases where no player chooses a unique number, there is no winner. For instance, suppose there is a LUIG with $N=3$ and $M=3$. There are three players, A, B, and C,

\footnotetext{
*We thank Angela Sutan and her colleagues at Laboratoire d'Expérimentation en Sciences Sociales et Analyse des Comportements (LESSAC) at Burgundy School of Business for their help in carrying out our experiments. We also thank Jean-Sébastien Gharbi for his help in preparing the experiment's instructions in French, and Jeremy Mercer for proof-reading our manuscript. Financial support from Japan Society for the Promotion of Science (JSPS) Grant-in-Aid for Young Scientists (B) (24710163), from Canon Europe Foundation under a 2013 Research Fellowship Program, and from JSPS and ANR under the Joint Research Project, Japan - France CHORUS Program, "Behavioural and cognitive foundations for agent-based models (BECOA)" (ANR-11-FRJA-0002) is gratefully acknowledged.

${ }^{\dagger}$ Faculty of Global and Science Studies, Yamaguchi University. 1677-1 Yoshida, Yamaguchi, Yamaguchi, 753-8541, Japan. E-mail: tyamada@yamaguchi-u.ac.jp

${ }^{\ddagger}$ GREDEG, Université de Nice Sophia Antipolis, Université Côte d'Azur, and IUF. 250 Rue Albert Einstein, 06560, Valbonne, France. E-mail: Nobuyuki.HANAKI@unice.fr.
} 
who each submit an integer between 1 and 3 . If the integers chosen by $\mathrm{A}, \mathrm{B}$, and $\mathrm{C}$ are 1,2 , and 3 , respectively, then $\mathrm{A}$ wins the game. If the integers chosen by $\mathrm{A}, \mathrm{B}$ and $\mathrm{C}$ are 1,1 , and 2, respectively, then $\mathrm{C}$ is the winner. And, as noted, if all of them choose the same integer, there is no winner.

LUIGs are highly simplified versions of real systems such as the Swedish lottery game Limbo where the player who chooses the lowest unique number wins a cash prize (Östling et al., 2011) and Lowest/Highest Unique Bid Auctions (LUBA/HUBA) like the Auction Air or Juubeo websites where players bid, by paying a fixed participation fee, on prizes such as electronic devices or jewelry and either the lowest or highest unique bid wins. These systems differ from LUIGs in that the exact number of players (or participants) is not known when participants are deciding which integer to choose or how much to bid. In addition, unlike with LUIGs or the Swedish lottery, in LUBA/HUBA scenarios, a winner has to pay the amount s/he bids in exchange for the item being auctioned. ${ }^{1}$

These types of real systems have been attracting much attention recently from scholars of various disciplines (Costa-Gomes and Shimoji, 2014; Eichberger and Vinogradov, 2008; Gallice, 2009; Houba et al., 2011; Juul et al., 2013; Mohlin et al., 2014, 2015; Otsubo et al., 2013; Pigolotti et al., 2012; Rapoport et al., 2009b; Raviv and Virag, 2009; Zhou et al., 2015). While the studies mentioned investigate these related systems theoretically and empirically, experimental studies on LUIGs and related systems are still scarce. Östling et al. (2011), Otsubo et al. (2013), and Chmura and Güth (2011) are three experimental studies that are closely related to ours. Östling et al. (2011) experimentally study a version of the Swedish lottery in which subjects were not informed of the exact number of players in the game. Otsubo et al. (2013) experimentally study a version of LUBA/HUBA in which subjects were informed of the number of players, $N$, and the strategy space, $\{1,2, . ., M\}$, for $(N, M) \in\{(5,4),(5,25),(10,25)\}$. But unlike our experiment in which the winner receives a fixed payoff regardless of the number chosen, the winner's payoff in Otsubo et al. (2013) depends on the number he or she has chosen. Chmura and Güth (2011) use experiments to study a three-player minority game. In a minority game, three or more odd-numbered players choose one of two options. Thus, a

\footnotetext{
${ }^{1}$ There are other differences depending on the auction site. For example, in a HUBA on the Juubeo website, participants can place multiple bids by paying a small fee for each additional bid and they are immediately informed whether their current bid is the current winning bid.
} 
three-player minority game is structurally equivalent to a LUIG with $N=3$ and $M=2$. The minority game originates from the "El Farol Bar" problem (Arthur, 1994) which is based on people independently deciding whether to go to a popular bar or not; if too many people independently choose to go to the bar, it will be too crowded and those who stayed at home are better off than those at the bar. The opposite is true when the bar is not too crowded. This problem has been extensively studied both by economists and physicists. See, among others, Challet and Zhang $(1997,1998)$ for theoretical analyses, and Bottazzi and Devetag (2003, 2007); Chmura and Pitz (2006); Devetag et al. (2011); Linde et al. (2014); Platkowski and Ramsza (2003) for experimental studies with larger numbers of players. The experimental method of Chmura and Güth (2011) is, however, different from ours in that they directly elicit a mixed strategy (a probability distribution over two choices) from each subject. In our experiment, each subject submits a pure strategy (i.e., an integer).

Furthermore, LUIGs are fertile ground for experimental study because unlike minority games where multiple players can win the game, LUIGs consider a situation with an extreme congestion effect because at most one player can win. Games with a congestion effect have applications for problems such as the choice of traffic routes (Selten et al., 2007) that are known to generate an interesting phenomenon called the Braess paradox, a situation exemplified by improvements in a road network actually worsening traffic problems (Morgan et al., 2009; Rapoport et al., 2009a). In situations with congestion effects, an interesting question is how players learn to either consciously or unconsciously coordinate their behavior so that inefficiencies due to congestion are reduced. Hanaki et al. (2011) theoretically examine this question in what they call "a parking problem." In their "parking problem," available options are clearly ordered in terms of their desirability which is the same for all players. Since each option can be taken by at most one player, when more than one player chooses the same option, only one of them obtains it. By applying a reinforcement learning model, Hanaki et al. (2011) show that ex ante homogeneous players separate themselves into "lucky" and "unlucky" ones. They show that some "lucky" players learn to choose "better options" all the time because their early successes in doing so reinforced these options as the right choice, but other "unlucky" players learn to choose "worse options" all the time because in the early stages of their 
learning processes they failed to obtain a good outcome when they had actually chosen the "better option." However, it is precisely because of the existence of the latter players who have settled into choosing "worse options" that the former group continues to have a positive experience from doing what they do, namely, choosing "better options."

In this paper, we aim to study such self-organization among players experimentally. In particular, we wish to gain insight into whether and how subjects separate themselves into different behavioral classes in situations with an extreme-congestion effect such as LUIGs. Recall that in LUIGs, the winning payoff is the same regardless of the number the winner has chosen. We expect this feature, which is absent in the LUBA or HUBA scenarios mentioned above, will facilitate the self-organization of subjects that we are interested in. In addition, by eliminating the round-by-round fluctuations in the number of players, we can focus on subjects' behavior in a stable (at least in terms of number of players) environment, which should again favor self-organization. Thus, we believe LUIGs offer a good starting point for studying self-organization among players.

We found that some subjects kept choosing the same number, while others switched their choices often. We also found that the first type of subject won the game more frequently than the latter type of subject. However, it should be noted that a strategy of sticking to the same number pays off in a LUIG only when other players do not employ the same strategy. Thus, it is the existence of the latter type of subjects that benefits the strategy employed by the former types. We also found that choices made by more than $1 / 3$ of subjects were not significantly different from those under the symmetric mixed-strategy Nash equilibrium (MSE) of the LUIG.

Below, we report experimental results for four LUIGs with varying numbers of players, $N$, and varying sets of integers from which players choose, $\{1,2, \cdots, M\}$. Namely, we consider $N \in\{3,4\}$ and $M \in\{3,4\}$. Given the exploratory nature of these experiments, the results we report in this paper are descriptive.

The rest of the paper is organized as follows: the next section explains the experiments; Section 3 summarizes the results of our experiments; and Section 4 ends the paper with a concluding remark. 
Table 1: Two games played in each session

\begin{tabular}{ccc}
\hline Session & Game 1 & Game 2 \\
\hline 1 & $(N, M)=(3,3)$ & $(N, M)=(3,4)$ \\
2 & $(N, M)=(3,4)$ & $(N, M)=(4,4)$ \\
3 & $(N, M)=(4,4)$ & $(N, M)=(4,3)$ \\
4 & $(N, M)=(4,3)$ & $(N, M)=(3,3)$ \\
5 & $(N, M)=(3,4)$ & $(N, M)=(3,3)$ \\
6 & $(N, M)=(3,3)$ & $(N, M)=(4,3)$ \\
7 & $(N, M)=(4,3)$ & $(N, M)=(4,4)$ \\
8 & $(N, M)=(4,4)$ & $(N, M)=(3,4)$ \\
\hline
\end{tabular}

\section{Experiments}

We consider four LUIGs with $N \in\{3,4\}$ and $M \in\{3,4\}$. Each subject played two separate LUIGs. We changed either $N$ or $M$, but not both, between the two games a subject played. Thus, we had eight pairs of games as shown in Table 1. Each LUIG was repeated 50 times with the same group of subjects. We call one play of a game a round. There was a non-binding time limit of 15 seconds for choosing an integer in each round. When the time limit was reached, a warning sign appeared on the screen to urge the subject to make a choice. After everyone in the group made their choices, the subjects were informed of the result of the round. The feedback consisted of whether a subject was a winner or not, in addition to the winning number for the round. Subjects were informed that the winning number was set to zero when there was no winner.

Once the 50 rounds of the first LUIG were completed, subjects were re-matched to form another group to play the second LUIG for 50 rounds. Subjects were initially told that they would play two LUIGs with 50 rounds each, but were not informed about the exact game (i.e., $N$ and $M$ ) until the start of each game. At the beginning of each game, they were reminded that the other subjects in their group would remain the same during the 50 rounds.

Subjects were paid according to the outcome of one randomly chosen round from each game. The winner of a game received 20 euros in addition to a participation fee of 10 euros. Thus the maximum a subject could earn was 50 euros. Subjects were paid in cash at the end of the experiment. ${ }^{2}$

\footnotetext{
${ }^{2}$ The English translation of the experiment's instructions can be found in the Appendix.
} 
Table 2: Probability of choosing each number under the symmetric mixed-strategy Nash equilibrium for the four LUIGs

\begin{tabular}{lrrrrrr}
\hline & $N$ & $M$ & 1 & 2 & 3 & 4 \\
\hline LUIG33 & 3 & 3 & 0.464 & 0.268 & 0.268 & \\
LUIG34 & 3 & 4 & 0.458 & 0.252 & 0.145 & 0.145 \\
LUIG43 & 4 & 3 & 0.449 & 0.426 & 0.125 & \\
LUIG44 & 4 & 4 & 0.448 & 0.425 & 0.126 & 0.002 \\
\hline
\end{tabular}

\section{Results}

Computerized experiments, implemented using z-Tree (Fischbacher, 2007), took place in January and February 2014 at the Laboratoire d'Expérimentation en Sciences Sociales et Analyse des Comportements (LESSAC), Burgundy School of Business (Dijon, France). 192 students who had never experienced a LUIG experiment participated. There were 24 students in each of the 8 sessions listed in Table 1. A session lasted between 65 and 85 minutes. Out of our 192 subjects, 11 earned 50 euros and 67 earned 30 euros. The remaining 114 subjects earned only the participation fee of 10 euros.

Because a LUIG has many asymmetric pure and mixed-strategy Nash equilibria that are payoff asymmetric, we used the unique symmetric mixed strategy Nash equilibrium (MSE) of the LUIG as our theoretical benchmark. Readers may find our choice of MSE as a benchmark rather puzzling given our interest in investigating whether subjects separate themselves by choosing to employ different types of strategies. But it is precisely because of this reason that we use the MSE as our benchmark. We seek to determine whether and how the observed behavior of subjects, individually as well as in aggregate, deviates from a theoretical benchmark that assumes symmetry.

The MSEs for the four LUIGs we have experimented with are summarized in Table $2 .^{3}$ We abbreviate the four LUIGs $(N, M)=(3,3),(N, M)=(3,4),(N, M)=(4,3)$, and $(N, M)=(4,4)$ using the terms LUIG33, LUIG34, LUIG43, and LUIG44, respectively.

Table 3 shows the relative frequencies of the observed winning numbers in the four LUIGs. We are pooling all the groups that played the relevant LUIG. For each LUIG, the predicted relative frequencies under the MSE are also reported. Recall that a winning number " 0 " represents a case without any winner. For three out of four LUIGs, namely,

\footnotetext{
${ }^{3}$ Östling et al. (2011) provide a succinct algorithm to calculate MSE in LUIGs.
} 
Table 3: Relative frequencies of observed winning numbers

\begin{tabular}{|c|c|c|c|c|c|}
\hline \multicolumn{3}{|c|}{ a. LUIG 33} & \multicolumn{3}{|c|}{ b. LUIG 34} \\
\hline & Expr. & MSE & & Expr. & MSE \\
\hline Winning number & & & Winning number & & \\
\hline 0 & $12.88 \%$ & $13.84 \%$ & 0 & $8.88 \%$ & $11.80 \%$ \\
\hline 1 & $40.50 \%$ & $39.99 \%$ & 1 & $43.31 \%$ & $40.38 \%$ \\
\hline 2 & $26.88 \%$ & $23.09 \%$ & 2 & $29.18 \%$ & $22.20 \%$ \\
\hline \multirow[t]{2}{*}{3} & $19.75 \%$ & $23.09 \%$ & 3 & $15.94 \%$ & $12.81 \%$ \\
\hline & & & 4 & $2.69 \%$ & $12.81 \%$ \\
\hline \multicolumn{3}{|c|}{ c. LUIG 43} & \multicolumn{3}{|c|}{ d. LUIG 44} \\
\hline & Expr. & MSE & & Expr. & MSE \\
\hline Winning number & & & Winning number & & \\
\hline 0 & $33.33 \%$ & $32.91 \%$ & 0 & $27.17 \%$ & $32.63 \%$ \\
\hline 1 & $27.50 \%$ & $30.09 \%$ & 1 & $32.42 \%$ & $30.17 \%$ \\
\hline 2 & $32.17 \%$ & $28.60 \%$ & 2 & $30.41 \%$ & $28.63 \%$ \\
\hline 3 & $7.00 \%$ & $8.40 \%$ & 3 & $8.33 \%$ & $8.47 \%$ \\
\hline & & & 4 & $1.67 \%$ & $0.01 \%$ \\
\hline
\end{tabular}

LUIG33, LUIG43, and LUIG44, the observed frequencies of winning numbers are very similar to what the MSE of each game predicts. The major difference between the prediction of the MSE and the experimental outcome is observed in LUIG34 in which "4" was much less frequently the winning number in the experiment compared to the MSE.

Although, on aggregate, we observed that the frequencies of winning numbers were not so different from the predictions under MSE except for in LUIG 34, if we compare the frequencies of the various outcomes (the sets of numbers chosen by subjects) to those predicted by the MSE, we find that in some groups they are significantly different from the prediction under the MSE (we call these non-MSE groups) and in other groups they are similar to the MSE predictions (MSE groups). We employ Kolmogorov-Smirnov (KS) tests to compare the data with the MSE predictions, and use $5 \%$ significance level in determining non-MSE and MSE groups. However, it should be noted again that except for LUIG 34, most of the groups in our data are classified as MSE groups according to the criterion used. See the number of two types of groups in each LUIG shown under the corresponding panel in Figure 1.

Figure 1 shows, for each of the four LUIGs, the average frequencies of set of chosen numbers for MSE groups (shaded) and non-MSE groups (black). The theoretical bench- 
a. LUIG 33

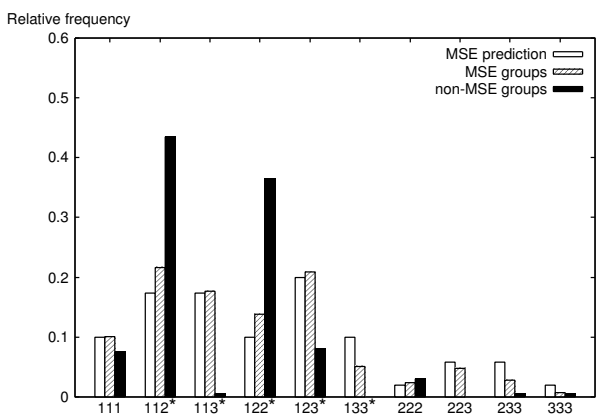

\# MSE group $=28$, \# non-MSE group $=4$

c. LUIG 43

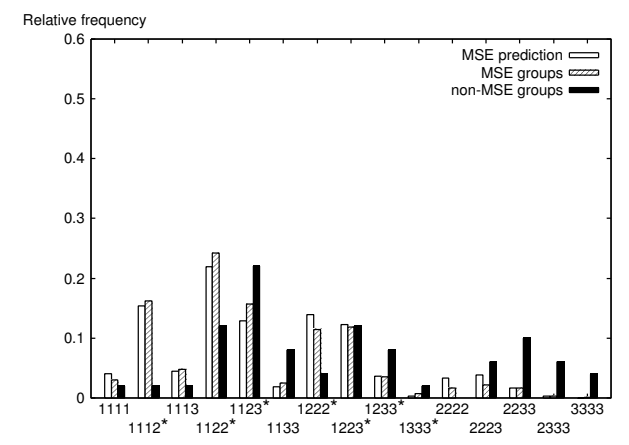

\# MSE group $=23, \#$ non-MSE group $=1$ b. LUIG 34

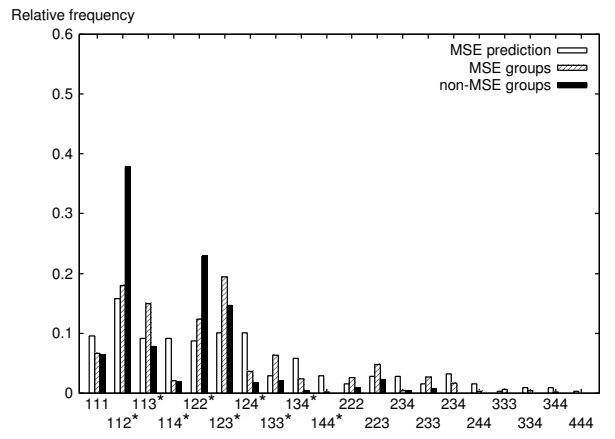

\# MSE group $=19$, \# non-MSE group $=13$

d. LUIG 44

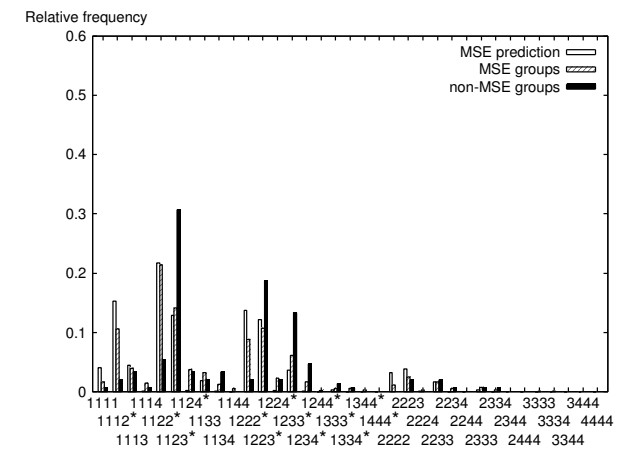

\# MSE group $=21$ \# non-MSE group $=3$

Figure 1: Histogram of the average relative frequencies of game outcomes (set of chosen number) under MSE (white), MSE groups (shaded), and non-MSE groups (black).

marks according to the MSE are also shown in white for each LUIG. It also indicates those outcomes that are equilibria under the pure strategy Nash equilibrium by " $*$ " next to the label in the $\mathrm{x}$-axis. What we can observe first is that those outcomes that are not supported by the pure strategy Nash equilibrium (those without "*" next to the label on the x-axis) are frequently observed, in particular, among MSE groups. For non-MSE groups, the observed outcomes tend to be the equilibria under the pure strategy Nash equilibrium. The noticeable differences between MSE and non-MSE groups in term of frequencies of outcomes are as follow: in LUIG 33 and LUIG 34, the outcomes (112) and (122) are less frequently observed in the former group than in the latter, while the outcome (123) is more frequently observed in the former group than in the latter; in LUIG 43 and LUIG 44, the outcomes (1112) or (1122) are more frequently observed in MSE groups than in non-MSE groups, while such outcomes as (1123) or (1233) that 
involve subjects choosing larger numbers are more frequently observed in the non-MSE groups than in MSE groups.

Overall, however, the MSEs seem to do a good job of organizing aggregate outcomes in the LUIGs we have considered. Next, we tested whether the choices made by each subject followed the predictions under the MSE in each LUIG.

Figure 2 shows, in simplexes, the relative submission frequencies for each integer for each subject in the four LUIGs. A point in a simplex represents a subject. Here we are pooling subjects from all the sessions who played the given LUIG. Thus, in each panel, there are total of 96 dots (subjects), plus the relative frequencies predicted by the MSE that is shown by a "*".

In Figure 2, the relative frequency of a subject submitting 1 is represented by the height of the point from the edge that is opposite to the apex labeled ' 1 '. The relative frequencies of the subject submitting other integers can be read in the same way in the figure. For games with $M=4$, we added together the relative frequencies of submitting the two largest integers because they were small compared to the others under their MSEs.

There are four types of dots in each panel: filled circle, filled triangle, unfilled circle, and unfilled triangle. These four types of dots represent whether the observed behavior of a subject represented is significantly different from those predicted by the MSE based on two criteria: the relative frequencies of chosen numbers (choice) and the frequency of changing one's choices from one round to another (change). ${ }^{4}$ For the choice criterion, subjects are considered to be MSE subjects if their choice frequencies were not statistically different, at $5 \%$ significance level, from those predicted by the MSE according to Kolmogorov-Smirnov (KS) tests. Otherwise, they are considered to be non-MSE subjects. For the change criterion, subjects are considered to be MSE subjects if their frequency of changing their choices between two consecutive rounds lies within the $95 \%$ confidence interval predicted by the MSE. Otherwise, they are considered to be non-MSE subjects.

In Figure 2, the classification under the choice criterion is shown with filled dots

\footnotetext{
${ }^{4}$ We thank an anonymous referee for suggesting that we consider the second criterion in addition to the first one.
} 


\section{a. LUIG33}

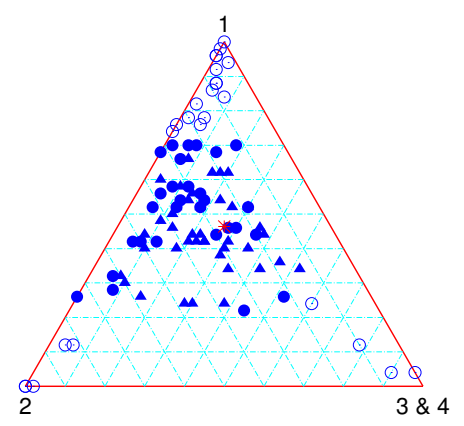

\begin{tabular}{lrr}
\hline choice \change & MSE & non-MSE \\
\hline MSE & 42 & 29 \\
non-MSE & 0 & 25 \\
\hline
\end{tabular}

c. LUIG43

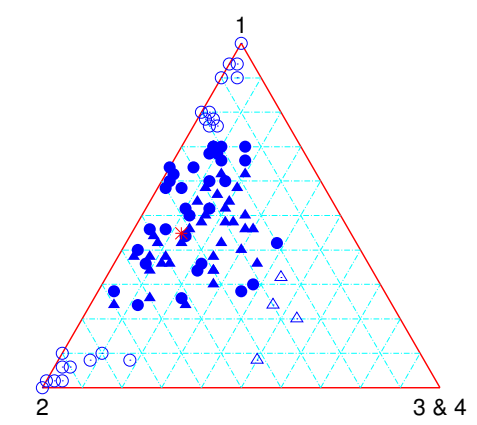

\begin{tabular}{lrr}
\hline choice \change & MSE & non-MSE \\
\hline MSE & 39 & 32 \\
non-MSE & 4 & 21 \\
\hline
\end{tabular}

b. LUIG34

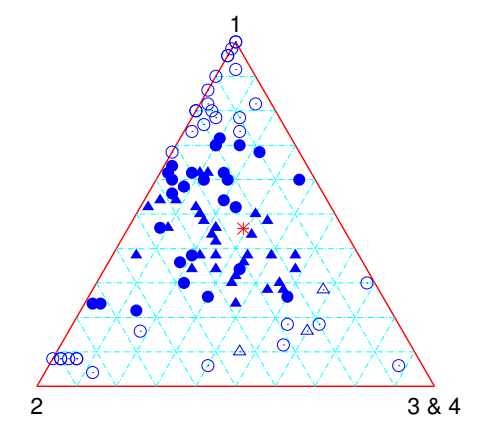

\begin{tabular}{lrr}
\hline choice \change & MSE & non-MSE \\
\hline MSE & 33 & 27 \\
non-MSE & 3 & 33 \\
\hline
\end{tabular}

d. LUIG44

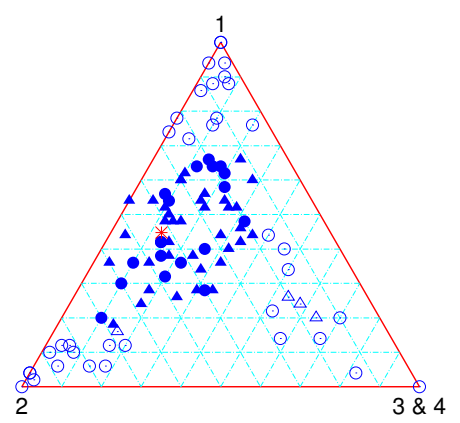

\begin{tabular}{lrr}
\hline choice \change & MSE & non-MSE \\
\hline MSE & 37 & 19 \\
non-MSE & 4 & 36 \\
\hline
\end{tabular}

$*:$ MSE, $\mathbf{\Delta}:$ MSE (choice) + MSE (change), •: MSE (choice) + non-MSE (change)
$\triangle:$ non-MSE (choice) + MSE (change), O: non-MSE (choice) + non-MSE (change)

Figure 2: Distributions of the relative frequencies of each number chosen. Each point corresponds to a subject. Subjects classified in two four classifications (1) MSE by both choice and change criteria (filled triangle), (2) MSE by choice by non-MSE by change criterion (filled circle), (3) non-MSE by choice by MSE by change criterion (unfilled triangle), and (4) non-MSE by both choice and change criteria (unfilled circle). 
a. LUIG 33 (95\% interval: $25 \sim 38$ )

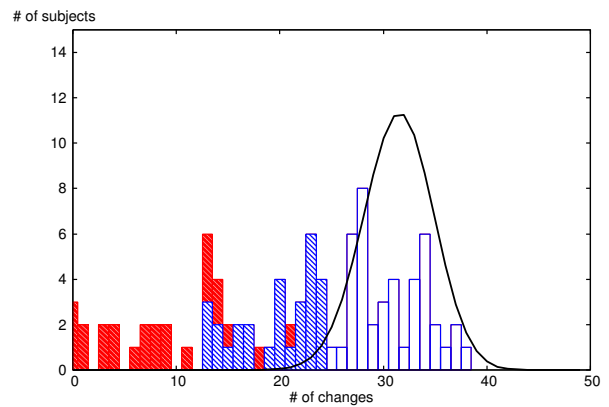

c. LUIG 43 (95\% interval: $23 \sim 36$ ) \# of subjects

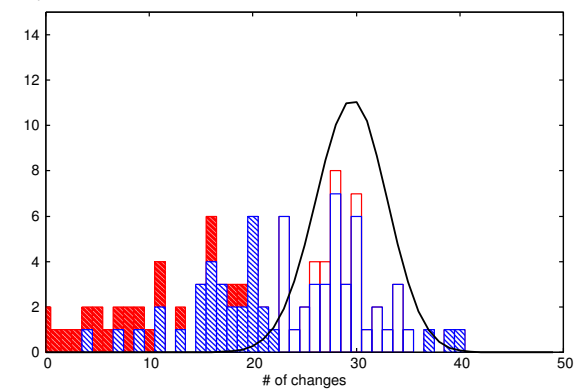

b. LUIG 34 (95\% interval: $27 \sim 40)$

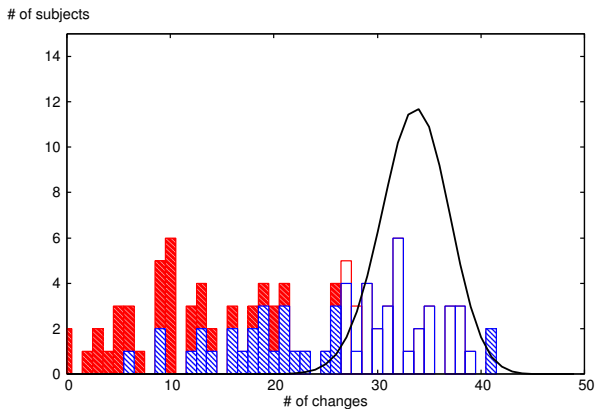

d. LUIG 44 (95\% interval: $23 \sim 36$ )

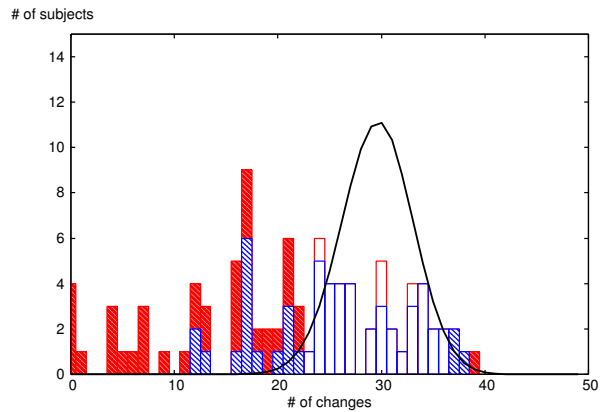

Figure 3: Histogram of the number of changes. The height of each bar represents the total number of subjects who have demonstrated the given number of changes in their choices. Blue and red part of bars: MSE and non-MSE subjects according to the choice criterion. Black line: MSE benchmark. Bars with and without shades: non-MSE and MSE subjects according to the change criterion.

(MSE) vs non-filled dots (non-MSE), and the classification under the change criterion is shown with triangle-shaped dots (MSE) vs circle-shaped dots (non-MSE). Thus, for example, those subjects who are classified as non-MSE subjects for both the choice and change criteria are depicted with non-filled circles, while those who are classified as MSE subjects for both criteria are depicted with filled triangles. The table below each panel shows the number of subjects classified into the four categories in the corresponding LUIG.

Figure 3 complements Figure 2 by showing the histograms of the number of changes for each LUIG. The height of each bar is cumulative in that it represents the total number of subjects who have demonstrated the given number of changes in their choices. Bars are distinguished into four styles: red vs blue and shaded vs non-shaded. Red and blue parts of each bar represent non-MSE and MSE subjects according to the choice cri- 
terion, respectively. Shaded and non-shaded bars represent non-MSE and MSE subjects according to the change criterion. The possible distribution of the frequency of changes according to the MSE prediction is shown with the black curve.

As one can note from the table below each panel in Figure 2, while most of the subjects who are classified as non-MSE under the choice criterion are also classified as non-MSE under the change criterion, this is not the case for those who are classified as MSE under the choice criterion. Between 35 and $45 \%$ of subjects classified as MSE subjects by the choice criterion did not change their choices between two consecutive rounds as frequently as the MSE predicts. Indeed, there is a positive correlation between the results of the classification based on these two criteria $(\phi=0.47) .{ }^{5}$

We find that an important fraction (more than 1/3) of our subjects were MSE subjects under both criteria in each of the four LUIGs. Out of 96 total subjects, the number of MSE subjects according to both criteria in LUIG33, LUIG34, LUIG43, and LUIG44 were $42,33,39$, and 37 , respectively. ${ }^{6}$ This finding is similar to Otsubo et al. (2013) who found that a majority of subjects behaved not significantly differently from what is predicted under the MSE in their experiment of a LUBA with $(N, M)=(5,4){ }^{7}$

Above analyses demonstrate that although majority of our subjects are classified as non-MSE subjects according to at least one of the two criteria, the group level outcomes do not deviate much from the MSE prediction. To understand this gap between individual and group level outcomes, we have conducted following exercise. We first fitted a simple reinforcement learning model to each of our subjects to obtain parameter values of the model. We then let these fitted learning models to play the same LUIG for 10000 periods. Simulation results show that, similarly to the experimental data, the group level

\footnotetext{
${ }^{5}$ Phi coefficients between the results of classification based on the two criteria for four LUIGs are: $0.52,0.47,0.34$, and 0.56 for LUIG 33, LUIG 34, LUIG 43, and LUIG 44, respectively.

${ }^{6}$ The number of MSE subjects will decline if we add more criteria in classifying our subjects into MSE or non-MSE. For example, in addition to the above mentioned two criteria, if we also consider the absence of statistically significant correlation in their choices between two consecutive periods, the number of MSE subjects become 39, 30, 37, and 33 in LUIG33, LUIG34, LUIG43, and LUIG44, respectively. Likewise, the above mentioned two criteria plus generalized runs test (Mielke and Berry, 2007), to test the randomness of the sequence of choices over 50 periods, show that the number of MSE subjects becomes 37, 25, 30, and 26 in LUIG33, LUIG34, LUIG43, and LUIG44, respectively.

${ }^{7}$ Otsubo et al. (2013) reported that the behaviors of the majority of subjects in LUBAs with $(N, M)=$ $(5,25)$ and $(N, M)=(10,25)(35$ out of 40 and 27 out of 50 , respectively) were significantly different from the MSE of the respective game. They found that many of their subjects in $(N, M)=(4,25)$ continued to choose the same number for a much longer duration than expected under the MSE. A lower fraction of subjects behaving significantly differently from the MSE in the LUBA with $(N, M)=(10,25)$ than with $(N, M)=(5,25)$ suggests that the size of $M$ relative to $N$ plays a role in inducing subjects to switch their choices across rounds.
} 
outcomes from the first 50 periods do not deviate significantly from MSE predictions in most of the simulations. However, if we consider the first 1000 periods or all the 10000 periods, they do deviate significantly in almost all the simulations. This suggests that the gap between individual and group level deviations from the MSE predictions in our experimental data may be partly due to the number of repetitions being 50 . The detail of this exercise is available from the authors upon request.

\subsection{Performance of MSE vs non-MSE subjects}

Let us diverge from testing whether our subjects behaved according to the MSE of the respective LUIG and move on to ask how often MSE and non-MSE subjects won the game. Because subjects are classified into four types based on the two criteria we employ, it is not possible for us to compare within-group differences in the frequencies of winning among those four types. We thus employ linear regression analysis with robust standard errors taking within-group clustering effects into account in order to correct for withingroup correlations. The results of these regression analyses are shown in Table 4. The dependent variable is the number of wins for each subject. Independent variables are dummy variables that are assigned a value of 1 if a subject is classified as MSE only under choice criterion (MSE choice only), as MSE only under change criterion (MSE change only), and as MSE under both choice and change criteria (MSE both). Otherwise, these dummy variables are assigned a value of 0 . We take those subjects who are classified as non-MSE according to both change and choice criteria as the benchmark. Negative and significant estimated coefficients on 'MSE choice only' show that those who are classified as MSE only under the choice criterion won significantly less frequently in each game compared to the benchmark subjects. Similarly, those classified as MSE only under the change criterion won less often than the benchmark subjects in all the games except for LUIG 33, but not significantly so. In LUIG 33, they won more often than the benchmark subjects, but again, not significantly so. Finally, those classified as MSE under both criteria won more frequently than the benchmark subjects, but again not significantly so. These results suggest that the classification based on the choice seems to have more significant explanatory power for the differences in the number of wins in LUIGs than the classification according to the change criterion. Thus, we focus on choice 
Table 4: Results of linear regression. Dependent variable: Number of wins.

\begin{tabular}{lcccc}
\hline \hline & LUIG 33 & LUIG 34 & LUIG 43 & LUIG 44 \\
\hline MSE choice only & -8.265 & -4.404 & -3.814 & -2.158 \\
& $(1.455)$ & $(1.403)$ & $(0.997)$ & $(1.276)$ \\
& $p<0.001$ & $p=0.004$ & $p=0.001$ & $p=0.104$ \\
MSE change only & 1.631 & -0.848 & -2.595 & -5.000 \\
& $(1.232)$ & $(1.740)$ & $(2.475)$ & $(1.963)$ \\
& $p=0.195$ & $p=0.629$ & $p=0.305$ & $p=0.018$ \\
MSE both & $n . a$ & 0.222 & 3.006 & 3.888 \\
& & $(2.009)$ & $(2.612)$ & $(2.282)$ \\
constant & & $p=0.913$ & $p=0.262$ & $p=0.102$ \\
& 19.920 & 18.182 & 11.095 & 11.000 \\
& $(0.869)$ & $(0.938)$ & $(0.971)$ & $(0.718)$ \\
No. of Obs & $p<0.001$ & $p<0.001$ & $p<0.001$ & $p<0.001$ \\
$R^{2}$ & 96 & 96 & 96 & 96 \\
\hline \hline
\end{tabular}

Note: Robust standard errors that correct for group clustering effects are reported in the parentheses.

criterion in the analysis to follow. Focusing on one criterion also allows us to examine within-group differences in the number of wins between the two types.

Table 5 summarizes, for each LUIG, the average frequencies of "winning" (\#wins) as well as the average frequencies of a subject changing his/her choices between two consecutive rounds (\#changes) depending on the composition of non-MSE and MSE subjects, according to the choice criterion alone, within a group. As one would expect from the results shown above, non-MSE subjects changed their choices much less frequently than MSE subjects in all four LUIGs. ( $p<0.01$ for all four LUIGs, Wilcoxon signed rank, WSR, test). In addition, non-MSE subjects won the game significantly more often than MSE subjects $\left(p<0.01\right.$ for all four LUIGs, WSR test). ${ }^{8}$ One can also observe that when there are more non-MSE subjects in a group, the difference in the average \#wins between non-MSE subjects and MSE subjects is larger in LUIG 33, LUIG 34, and LUIG 44.

The effectiveness of a non-MSE strategy over a MSE strategy has also been reported in a minority game (Chmura and Pitz, 2006). It seems that in LUIGs as well as in minority games, it pays to be stubborn and to stick with the same choice, although such

\footnotetext{
${ }^{8}$ We employ groups as an independent observation in carrying out these statistical tests. That is, these $p$-values are based on the within-group differences of the average \#changes and the average \#wins for non-MSE and MSE subjects.
} 
Table 5: Differences of performance with respect to the constitution of players ( $p$-values are from Wilcoxon signed rank test.)

a. LUIG 33

\begin{tabular}{rrrrrrr}
\hline & & \multicolumn{2}{c}{ non-MSE } & \multicolumn{2}{c}{ MSE } \\
\#non-MSE & \#MSE & \#groups & \#wins & \#changes & \#wins & \#changes \\
\hline 0 & 3 & 15 & & & 14.42 & 26.13 \\
1 & 2 & 9 & 17.00 & 11.89 & 12.17 & 27.50 \\
2 & 1 & 8 & 21.38 & 5.94 & 3.50 & 24.00 \\
3 & 0 & 0 & - & - & & \\
\hline$p<0.001$ (\#wins),$p<0.001$ (\#changes) & & &
\end{tabular}

b. LUIG 34

\begin{tabular}{rrrrrrr}
\hline & & \multicolumn{4}{c}{ non-MSE } & \multicolumn{2}{c}{ MSE } \\
\#non-MSE & \#MSE & \#groups & \#wins & \#changes & \#wins & \#changes \\
\hline 0 & 3 & 9 & & & 14.89 & 26.96 \\
1 & 2 & 12 & 17.83 & 14.67 & 13.79 & 26.21 \\
2 & 1 & 9 & 19.11 & 9.94 & 8.11 & 26.78 \\
3 & 0 & 2 & 15.67 & 10.83 & & \\
\hline$p=0.003$ (\#wins), $p<0.001$ (\#changes) & & &
\end{tabular}

c. LUIG 43

\begin{tabular}{rrrrrrr}
\hline & \multicolumn{10}{c}{ non-MSE } & \multicolumn{2}{c}{ MSE } \\
\#non-MSE & \#MSE & \#groups & \#wins & \#changes & \#wins & \#changes \\
\hline 0 & 4 & 5 & & & 9.15 & 23.10 \\
1 & 3 & 14 & 10.79 & 14.14 & 7.29 & 24.57 \\
2 & 2 & 4 & 12.25 & 8.25 & 4.50 & 22.88 \\
3 & 1 & 1 & 6.00 & 6.00 & 2.00 & 11.00 \\
4 & 0 & 0 & - & - & & \\
\hline$p=0.003$ (\#wins), & & 0 & 0.001 & (Hchanges)
\end{tabular}

$p=0.003$ (\#wins), $p<0.001$ (\#changes)

d. LUIG 44

\begin{tabular}{rrrrrrr}
\hline & & \multicolumn{2}{c}{ non-MSE } & \multicolumn{2}{c}{ MSE } \\
\#non-MSE & \#MSE & \#groups & \#wins & \#changes & \#wins & \#changes \\
\hline 0 & 4 & 3 & & & 8.17 & 31.42 \\
1 & 3 & 10 & 10.50 & 21.70 & 9.50 & 25.10 \\
2 & 2 & 5 & 11.50 & 13.00 & 6.20 & 24.10 \\
3 & 1 & 4 & 10.75 & 10.50 & 3.00 & 23.00 \\
4 & 0 & 2 & 8.88 & 11.75 & & \\
\hline
\end{tabular}

$p=0.004$ (\#wins), $p=0.006$ (\#changes) 
a strategy only works when there are others who frequently change their choices.

\subsection{Behavior in two LUIGs}

Let us now go one step further by making use of the fact that each subject played two LUIGs in our experiment. In the analyses above, within each LUIG we have classified subjects as either MSE or non-MSE. It is therefore possible that the same subject is classified as a MSE subject in one game and a non-MSE subject in another. Since we are interested in subjects separating themselves into different behavioral groups, it is interesting to check whether the classification of our subjects remains the same across the two LUIGs they played and, in case it changes for some and remains the same for others, to investigate what we can learn from the differences in their behavior. In doing so, we ignore the differences across the four LUIGs because, as noted above, in all four LUIGs those subjects classified as non-MSE according to their choice frequencies won significantly more often and changed their choices between two consecutive rounds significantly less often than those classified as MSE.

We use " $t 1 \rightarrow t 2$ " to denote those subjects who were classified as $t 1$ (MSE vs nonMSE) in Game 1 and $t 2$ (MSE vs non-MSE) in Game 2. The number of subjects who are 'MSE $\rightarrow$ MSE', 'MSE $\rightarrow$ non-MSE', 'non-MSE $\rightarrow$ MSE', and 'non-MSE $\rightarrow$ non-MSE' subjects in our sample are $99,46,14$, and 33 , respectively.

We have conducted the following simple regression analysis. Our dependent variable is assigned the value 1 if a subject changed his/her choices between rounds $r$ and $r+1$, and is assigned the value 0 otherwise. We then regressed this, using a logit specification, on a dummy variable that captures whether the subject lost the game in round $r$ or not, and the interaction terms between the dummy with other dummy variables representing the classification of the subject, as well as two variables that characterize the LUIG the subject played, $N$ and $M$. The dummy variables classify subjects as Type 1, 2, or 3 . These types are defined as follows: Type $1=1$ if the subject is 'non-MSE $\rightarrow$ MSE' and zero otherwise, Type $2=1$ if 'MSE $\rightarrow$ non-MSE' and zero otherwise, and Type $3=1$ if 'MSE $\rightarrow$ MSE' and zero otherwise. The remaining 'non-MSE $\rightarrow$ non-MSE' are used as benchmark, and we call them Type 0 below. We compute robust standard errors taking within-group clustering effects into account in order to correct for within-group 
correlations. We run this regression separately for Games 1 and 2. We also do a similar exercise by regressing the same dependent variable on the dummy variable that captures whether the subject won the game in round $r$ instead of losing in round $r$, as well as all the interactions with subject's type dummies and $N$ and $M$.

The results of logit regressions are reported in Table 6 . The estimated coefficients reveal interesting differences between our benchmark Type 0 subjects who remained nonMSE in both games, and those who switch between non-MSE and MSE (Type 1 and Type 2 as defined above), as well as those who remained MSE in both games (Type 3). Let's first consider Type 0 and Type 1, who are both classified as non-MSE in Game 1. While there is no significant difference between these two types in their tendency to change their choice following a win, Type 1 subjects changed their choices significantly more often (at 10\% level) following a loss than Type 0 subjects in Game 1. Between Type 0 and Type 2, who are both classified as non-MSE in Game 2 but have different classifications in Game 1, we find no significant differences in their tendencies to change their choices following either a win or a loss in Game 1. However, we do find a significant difference in their tendency to change their choices following a loss in Game 2 but no such tendency following a win in Game 2. Namely, Type 2 subjects changed their choice significantly more frequently following a loss than Type 0 subjects. Finally, between Type 0 and Type 3 , the latter subjects changed their choices significantly more frequently both following a loss and a win in both Game 1 and Game 2 than the former.

Thus, what really separates the subjects seems to be their tendencies to change their choices following a loss. Subjects who are consistently classified as non-MSE in both games change their choices significantly less often following losses compared to those who are classified as non-MSE in one game and MSE in another. Note again that this difference in the tendencies to change their choices following a loss is observed in games where two types of subjects are both classified as non-MSE. Those who are consistently classified as MSE in both games change their strategy more often than those non-MSE subjects regardless of the outcome (a win or a loss) of the game. 
Table 6: Result of logit regression. Dependent variable $=1$ if a subject changed their choice between rounds $r$ and $r+1$.

\begin{tabular}{|c|c|c|c|c|}
\hline & \multicolumn{2}{|c|}{$\mathrm{D}=1$ if lost in round $r$} & \multicolumn{2}{|c|}{$\mathrm{D}=1$ if won in round $r$} \\
\hline & Game 1 & Game 2 & Game 1 & Game 2 \\
\hline \multirow[t]{2}{*}{$\mathrm{D}$} & $\begin{array}{c}-0.308 \\
(0.361)\end{array}$ & $\begin{array}{c}-0.993 \\
(0.424)\end{array}$ & $\begin{array}{c}-0.882 \\
(0.438)\end{array}$ & $\begin{array}{r}-0.699 \\
(0.426)\end{array}$ \\
\hline & $p=0.092$ & $p=0.019$ & $p=0.044$ & $p=0.101$ \\
\hline \multirow[t]{2}{*}{$\mathrm{D} \times$ type 1} & 1.076 & 0.687 & 1.088 & 0.231 \\
\hline & $(0.613)$ & $(0.684)$ & $\begin{array}{r}(0.708) \\
=-0124\end{array}$ & (0.758) \\
\hline \multirow{3}{*}{$\mathrm{D} \times$ type 2} & & & & \\
\hline & 0.405 & 1.212 & 0.557 & $\begin{array}{c}0.937 \\
(0.607)\end{array}$ \\
\hline & $p=0.401$ & $p=0.037$ & $p=0.309$ & $p=0.123$ \\
\hline \multirow[t]{3}{*}{$\mathrm{D} \times$ type 3} & 1.037 & 1.196 & 1.120 & 0.911 \\
\hline & $(0.475)$ & $(0.441)$ & $(0.539)$ & $(0.494)$ \\
\hline & $p=0.029$ & $p=0.007$ & $p=0.038$ & $p=0.065$ \\
\hline \multirow[t]{3}{*}{$N$} & 0.121 & 0.275 & 0.054 & 0.281 \\
\hline & $(0.339)$ & 0.284 & $(0.327)$ & $(0.279)$ \\
\hline & $p=0.720$ & $p=0.332$ & $p=0.868$ & $p=0.314$ \\
\hline \multirow[t]{3}{*}{ M } & 0.526 & 0.140 & 0.482 & 0.134 \\
\hline & $(0.337)$ & 0.277 & $(0.331)$ & $(0.276)$ \\
\hline & $p=0.119$ & $p=0.612$ & $p=0.145$ & $p=0.627$ \\
\hline \multirow[t]{3}{*}{ constant } & -2.240 & -1.685 & -1.746 & -1.683 \\
\hline & $(1.640)$ & $(1.431)$ & $(1.536)$ & $(1.454)$ \\
\hline & $p=0.172$ & $p=0.239$ & $p=0.256$ & $p=0.247$ \\
\hline No. of Obs & 9408 & 9408 & 9408 & 9408 \\
\hline$R^{2}$ & 0.032 & 0.028 & 0.019 & 0.011 \\
\hline log likelihood & -6302.14 & -6278.71 & -6387.71 & -6391.28 \\
\hline
\end{tabular}

Note: Robust standard errors that correct for group clustering effects are reported in the parentheses. 


\section{Concluding Remark}

In this paper, we used laboratory experiments to study how subjects play Lowest Unique Integer Games (LUIGs) and to attempt to determine if and how subjects self-organize into groups behaving differently. We considered four LUIGs with the number of players $(N)$ being 3 or 4 , and the maximum integer each player can choose $(M)$ being 3 or 4 . We found that the choices made by more than $1 / 3$ of our subjects over 50 rounds of a LUIG were not significantly different from those predicted under the MSE of the LUIG. We also found that the subjects who won more often were those who behaved significantly differently from the MSE prediction by keep choosing the same number. However, such a strategy of choosing the same number only works in a LUIG if others do not employ the same strategy; otherwise, concurrent strategies of not changing choices could lead to an extreme congestion effect with no winners, i.e. multiple subjects repeatedly choosing the lowest number available. And we found that the distinguishing feature among our subjects when playing LUIGs was their tendencies to change their choices following a loss. Those who changed their choices significantly less often following a loss were the ones who won the game more often. These results provide experimental insight into both the manner in which LUIGs are played and how subjects self-select in situations where there is the congestion effect.

Future research may include exploring the effect of changing the amount of feedback subjects receive after each round of a game. For example, in addition to informing subjects about the winning number as we did in our experiment, one can consider informing subjects about all of the submitted numbers to investigate how providing more detailed feedback influences subjects' behavior. Other fruitful avenues for future research include eliciting a mixed strategy directly from subjects as done by Chmura and Güth (2011) for a three-player minority game, or eliciting a behavioral rule (repeated game strategy) as done by Linde et al. (2014) to better understand the behavior of subjects in LUIGs. The latter is particularly interesting because our subjects played the same LUIG repeatedly with the same group of subjects. Expanding the analyses to include repeated game strategies in such environments have been shown to provide rich insights in various two-player games, such as Prisoners' Dilemma, Coordination, Chicken, and 
Battle-of-the-Sexes, by Hanaki et al. (2005) and Ioannou and Romero (2014). We expect it will do the same in LUIGs. It is also of interest to gather more data on individual characteristics such as time and risk preferences as well as competitiveness to investigate whether and how they are related to the observed behavior in LUIGs.

\section{References}

ARThUR, W. B. (1994): "Inductive reasoning and bounded rationality," American Economic Review (Papers and Proceedings), 84, 406-411.

Bottazzi, G. and G. Devetag (2003): "A laboratory experiment on the minority game," Physica A, 324, 124-132.

_ (2007): "Competition and Coordination in Experimental Minority Games," Journal of Evolutionary Economics, 17, 241-275.

Challet, D. And Y.-C. Zhang (1997): "Emergence of cooperation and organizaton in an evolutionary game," Physica A, 246, 407-418.

- (1998): "On the minority game: Analytical and numerical studies," Physica A, $256,514-532$.

Chmura, T. And W. Güth (2011): "The minority of three-game: An experimental and theoretical analysis," Games, 2, 333-354.

Chmura, T. And T. Pitz (2006): "Successful strategies in repeated minority games," Physica A, 363, 477-480.

Costa-Gomes, M. A. And M. Shimoji (2014): "Theoretical approaches to lowest unique bid auctions," Journal of Mathematical Economics, 52, 16-24.

Devetag, G., F. Pancotto, and T. Brenner (2011): "The Minority Game Unpacked: Coordination and Competition in a Team-based Experiment," Ceel working paper 2-11, Computable and Experimental Economics Laboratory, Trento, Italy. 
Eichberger, J. AND D. Vinogradov (2008): "Least unmatched price auctions: a first approach," Discussion Paper Series 471, University of Heidelberg, Department of Economics.

FischBacher, U. (2007): "z-Tree: Zurich toolbox for ready-made economic experiments," Experimental Economics, 10, 171-178.

Gallice, A. (2009): "Lowest unique bid auctions with signals," Working Paper 112, Collegio Carlo Alberto.

Hanaki, N., A. Kirman, And M. Marsili (2011): "Born under a lucky star?" Journal of Economic Behavior and Organization, 77.

Hanaki, N., R. Sethi, I. Erev, and A. Peterhansl (2005): "Learning strategy," Journal of Economic Behavior and Organization, 56, 523-542.

Houba, H., D. "van der LaAn", And D. Veldhuizen (2011): "Endogenous entry in lowest-unique sealed-bid auctions," Theory and Decision, 71, 269-295.

Ionnnou, C. A. And J. Romero (2014): "A generalized approach to belief learning in repeated games," Games and Economic Behavior, 87, 178-203.

Juul, J., A. Kianercy, S. Bernhardsson, and S. Pigolotti (2013): "Replicator dynamics with turnover of players," Physical Review E, 88, 022806.

Linde, J., J. Sonnemans, And J. Tuinstra (2014): "Strategies and Evolution in the Minority Game: A Multi-Round Strategy Experiment," Games and Economic Behavior, 86, 77-95.

Mielke, Jr., P. W. And K. J. Berry (2007): Permutation Methods: A Distance Function Approach, Springer Series in Statistics, New York, NY: Springer, second ed.

Mohlin, E., R. Östling, And J. T.-Y. WAng (2014): "Learning by imitation in games: Theory, field, and laboratory," Discussion Paper Series 734, Department of Economics, University of Oxford.

[ (2015): "Lowest unique bid auctions with population uncertainty," Economics Letters, 134, 53-57. 
Morgan, J., H. Orzen, And M. Sefton (2009): "Network architecture and traffic flows: Experiments on the Pigou-Knight-Downs and Braess Paradox," Games and Economic Behavior, 66, 348-372.

Östling, R., J. T.-Y. Want, E. Y. Chou, and C. F. Camerer (2011): “Testing Game Theory in the Field: Swedish LUPI Lottery Games," American Economics Journal, Microeconomics, 3, 1-33.

Otsubo, H., A. Rapoport, W. E. Stein, and B. Kim (2013): "Behavioral patterns in lowest and highest unique bid auctions," in Bidding Types, Strategies and the Impact of Irrationality, ed. by M. K. Lim, New York, NY: Nova Publishers, chap. 3, 39-66.

Pigolotti, S., S. Bernhardsson, J. Juul, G. Galster, and P. Vivo (2012): "Equilibrium strategy and population-size effects in lowest unique bid auctions," Physical Review Letters, 108, 088701-1 - 088701-5.

Platkowski, T. and M. Ramsza (2003): "Playing minority game," Physica A, 323, $726-734$

Rapoport, A., T. Kugler, S. Dugar, and E. J. Gisches (2009a): "Choice of routes in congested trafiic networks: Experimental tests of the Braess Paradox," Games and Economic Behavior, 65, 538-571.

Rapoport, A., H. Otsubo, B. Kim, and W. E. Stein (2009b): "Unique bid auction games," Jena Economic Research Papers 2009-005.

Raviv, Y. AND G. ViRAG (2009): "Gambling by auction," International Journal of Industrial Organization, 27, 369-378.

Selten, R., T. Chmura, T. Pitz, S. Kube, and M. Schreckenberg (2007): "Commuters route choice behaviour," Games and Economic Behavior, 394-406.

Zhou, C., H. Dong, R. Hu, And Q. Chen (2015): "Smarter than others? Conjectures in lowest unique bid auctions," Plos One, 10, e0122923. 


\section{A Instructions}

We distributed a handout to our subjects and the experimenter read the script aloud.

The handout with the script is attached to this manuscript as a separate file. 


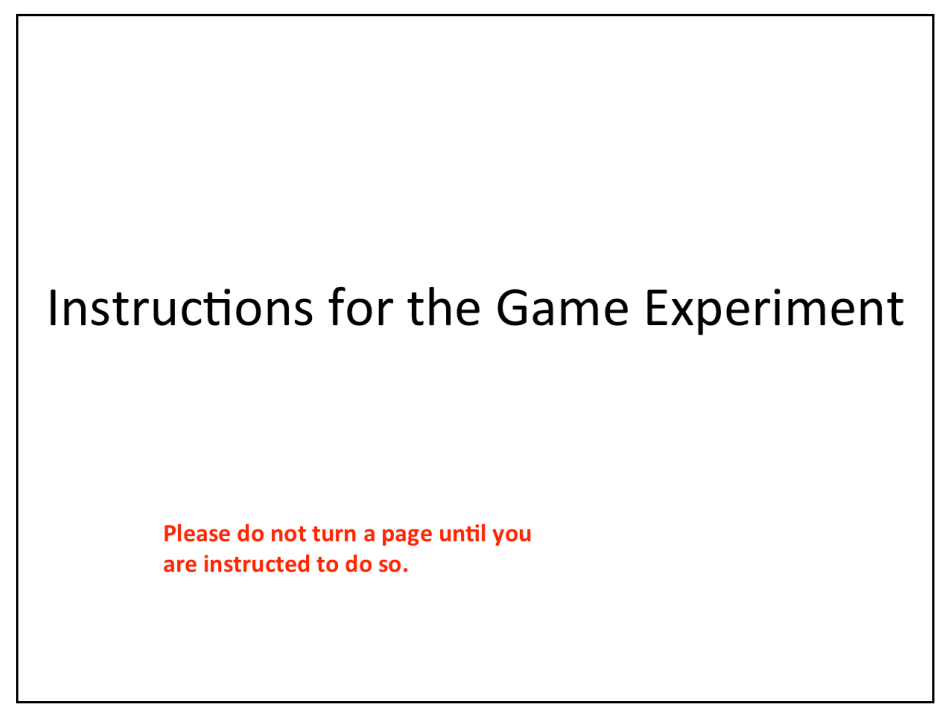

(After the quiz) Thank you.

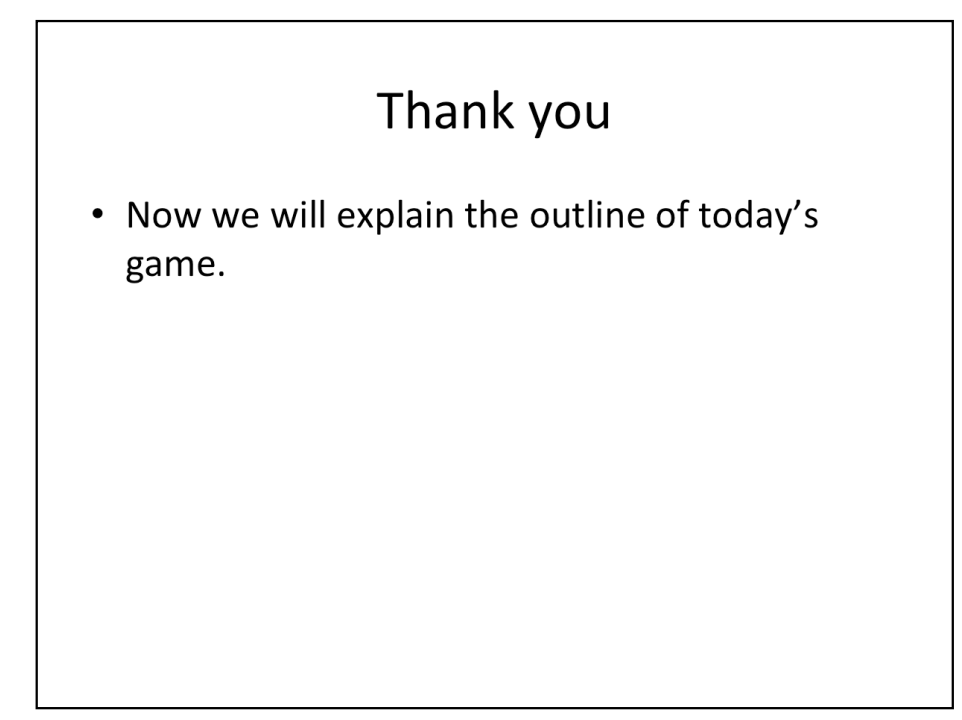

Now we will explain the outline of today's game.

Go on to the next page. 


\section{Outline of today's game}

- The game you are going to play is as follows:

- You will be a member of a group consisting of $N$ players.

- Before the start of a game, the computer will randomly determine the members of your group.

- Your group will not change within the game (there are 50 rounds in a game).

- The number of players (including you) will be indicated on the screen.

- But you will not be informed of the identity of the other players in your group.

\section{The game you are going to play is as follows:}

You will be a member of a group consisting of $\mathrm{N}$ players.

Before the start of a game, the computer will randomly determine the members of your group.

- Your group will not change within the game (There are 50 rounds in a game).

- The number of players (including you) will be indicated on the screen.

- But you will not be informed of the identity of the other players in your group.

\section{Rules of a Game}

- In each round of a game, each of you are asked to choose an integer between 1 and $M$.

- M will be clearly indicated on your computer screen.

- The winner in the group for the round is the one who has chosen the smallest number that is not chosen by anyone else in the group.

- If there is NOT such a member of the group, there is no winner.

- We will explain the rules of the game with a few examples.

In each round of a game, each of you are asked to choose an integer between 1 and $\mathrm{M}$. $\mathrm{M}$ will be clearly indicated on your computer screen.

(A little bit slowly)

The winner in the group for the round is the one who has chosen the smallest number that is not chosen by anyone else in the group.

If there is NOT such a member of the group, there is no winner.

We will explain the rules of the game with a few examples.

Go on to the next page. 


\section{Examples (1/5)}

- Consider a game such that:

-4 players ( $A, B, C$ and $D)$ are in a group

- Each player chooses an integer between 1 and 4 .

Now, let us consider the following game. This game has four players, A, B, C and D, and each of them chooses an integer between 1 and 4 .

\section{Examples (2/5)}

- Example 1:

- Let's imagine that players have chosen the following numbers:
Player
A $\quad$ B $\quad$ C $\quad$ D
Submission 12234

=> Player A wins.

\section{Let's imagine that players have chosen the following numbers:}

If Player A chooses 1, B chooses 2, C chooses 3 and D chooses 4, then Player A wins this game because 1 is the smallest integer that is NOT chosen by anyone else.

Go on to the next page. 


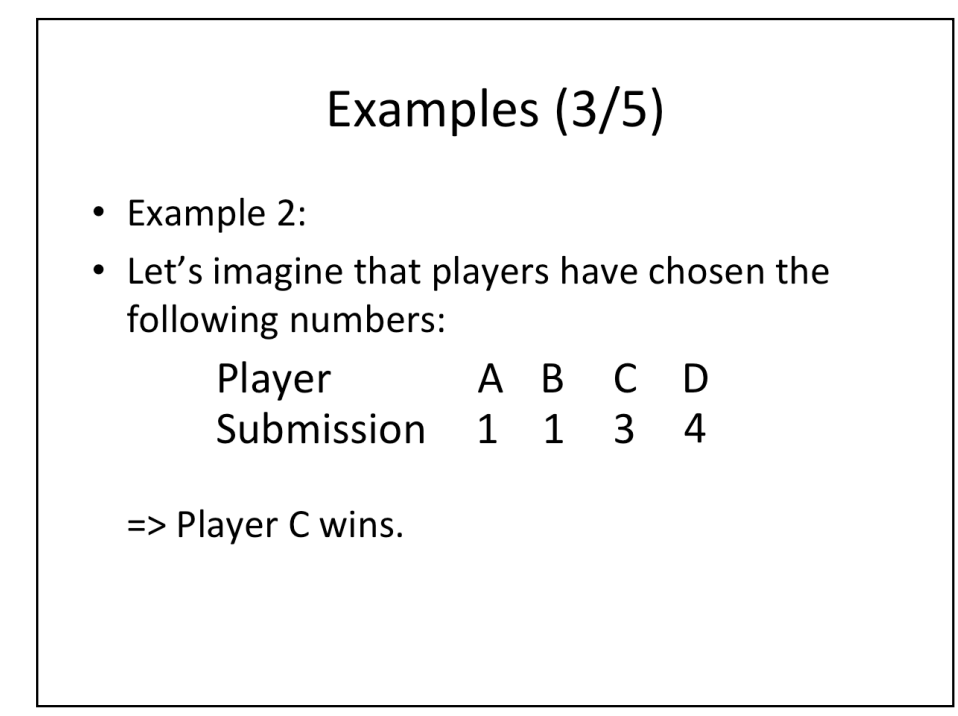

Second, let's imagine, players have chosen the following numbers:

Players A and B choose $1, C$ chooses 3 and D chooses 4 . In this case, Player C wins this game because 1 is chosen by two players and 3 is the smallest

integer that is NOT chosen by anyone else.

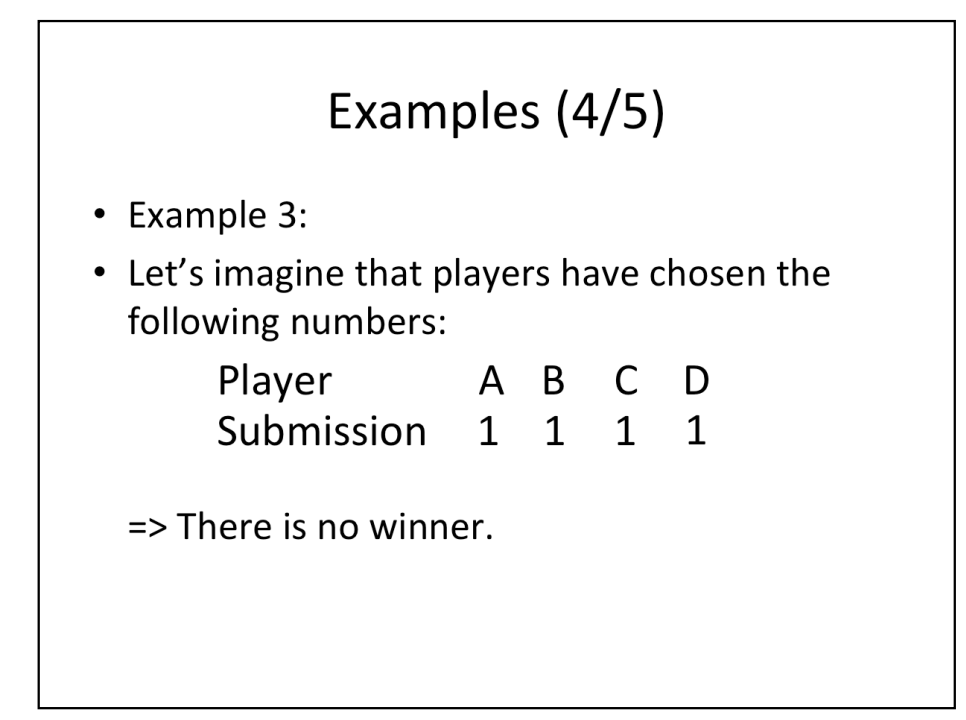

Thirdly, let's imagine, players have chosen the following numbers:

All of them choose 1 . In this case, there is no winner because there is no integer that is NOT chosen by anyone else.

Go on to the next page. 


\section{Examples (5/5)}

- Example 4:

- Let's imagine that players have chosen the following numbers:
Player
A $\quad$ B $\quad C \quad$ D
Submissio
$\begin{array}{llll}1 & 1 & 2 & 2\end{array}$

$\Rightarrow>$ There is no winner.

\section{Procedure of today's experiment}

- In today's experiment, all of you will play two kinds of games like this.

- You will be divided into several groups.

- Each group has three or four players.

- The number of players in your group and the range of numbers you can choose from will be clearly indicated on your screen.

- During the 50 rounds of a game experiment, the members of your group will not change.

Fourthly, let's imagine, players have chosen the following numbers:

Players $A$ and $B$ choose 1 and Players $C$ and $D$ choose 2 . In this case, there is also no winner because both integers are chosen by two players.

In today's experiment, all of you will play two kinds of this game.

You will be divided into several groups.

- Each group has three or four players.

- The number of players in your group and

the range of numbers you can choose from will be clearly indicated on your screen at the beginning of each game.

During the 50 rounds of a game experiment, the members of your group will not change.

Go on to the next page. 


\section{Reward}

- In addition to the participation fee of 10 euros, the winner of one randomly chosen round of each game

will be rewarded with 20 euros.

- One out of 50 rounds from Game 1 and another out of 50 rounds from Game 2 will be chosen randomly at the end of the experiment to be used for payment.

- Thus, you can earn a maximum of 40 euros + the participation fee.

- At the end of each round, you will be informed whether you won in the round.

- At the end of the experiment, you will be informed which round was chosen in each game.

In addition to the participation fee of 10 euros, the winner of one randomly chosen round of each game

- One out of 50 rounds from Game 1 and another out of 50 rounds from Game 2 will be chosen randomly at the end of the experiment to be used for payment.

-Thus, you can earn the maximum of 40 euros + the participation fee.

- At the end of each round, you will be informed whether you won in the round.

-At the end of the experiment, you will be informed which round was chosen in each game.
Flow of the game experiment (1/4)

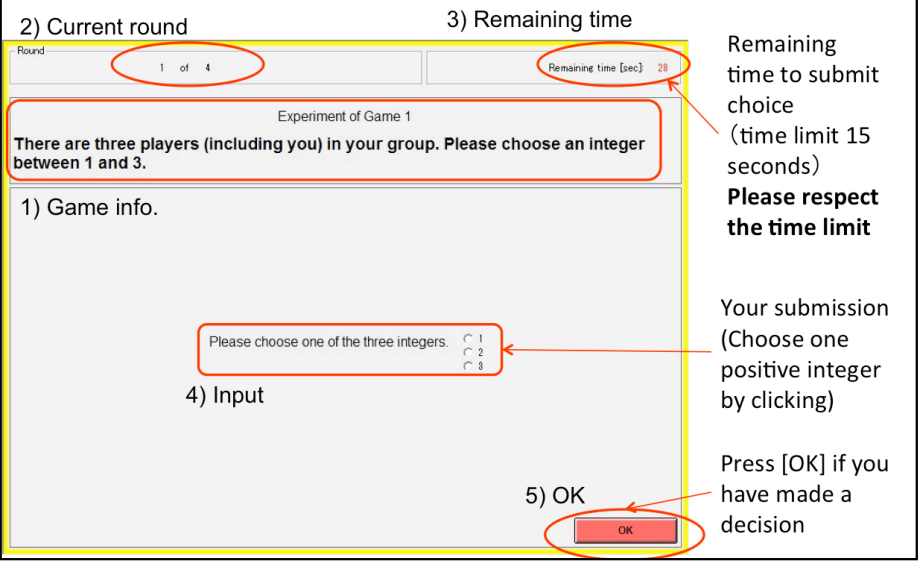

You can see the screenshot of the interface. This interface has five parts: Game information

Tells you what kind of game you are playing.

-Current round

Informs you of the current round of the experiment.

-Remaining time

This shows the remaining time to entering your choice.

The time limit to enter your choice is 15 seconds.

When the time has elapsed, a red warning message will flash at the top right corner of your screen.

-Input

There will be three or four buttons. By clicking one of them, your choice is temporarily determined.

-OK

Submits your decision to our server when pressed. If you forget to choose one integer, a caution screen appears.

Go on to the next page. 
Flow of the game experiment (2/4)

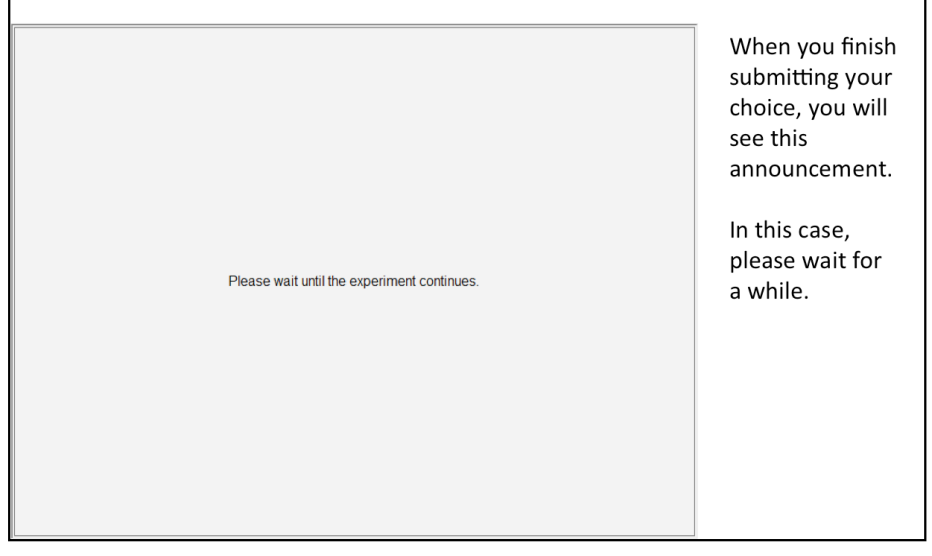

When you finish submitting your choice, you will see this announcement. In this case, please wait for a while.

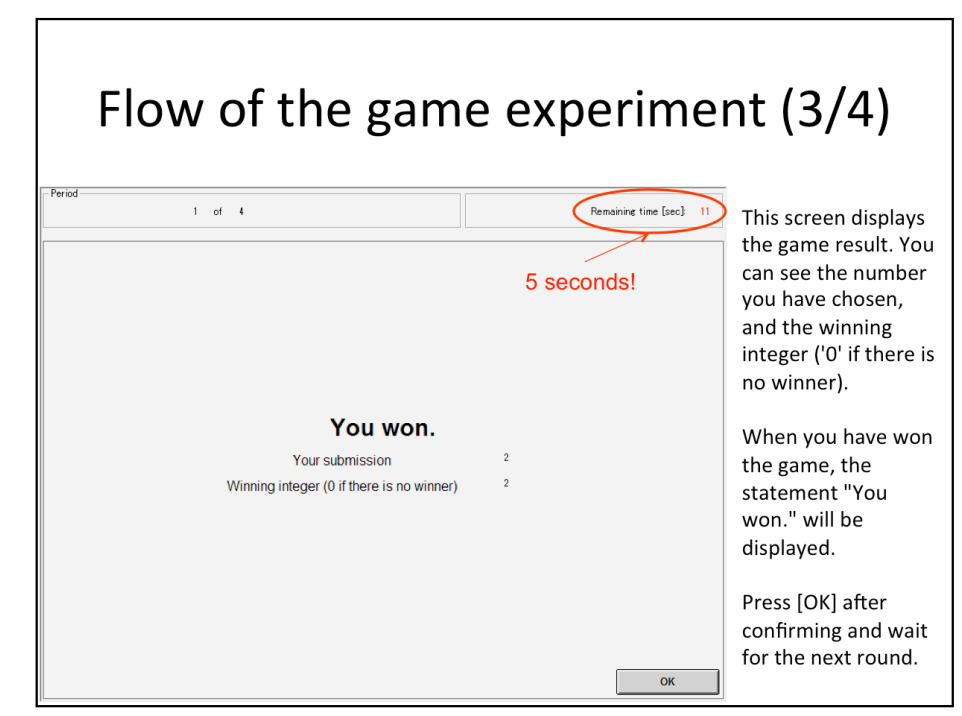

This screen displays the game result. You can see your chosen integer and the winning integer (' $O$ ' if there is no winner).

When you win, the statement "You won." will be displayed.

Press [OK] after confirming and wait for the next round.

Go on to the next page. 


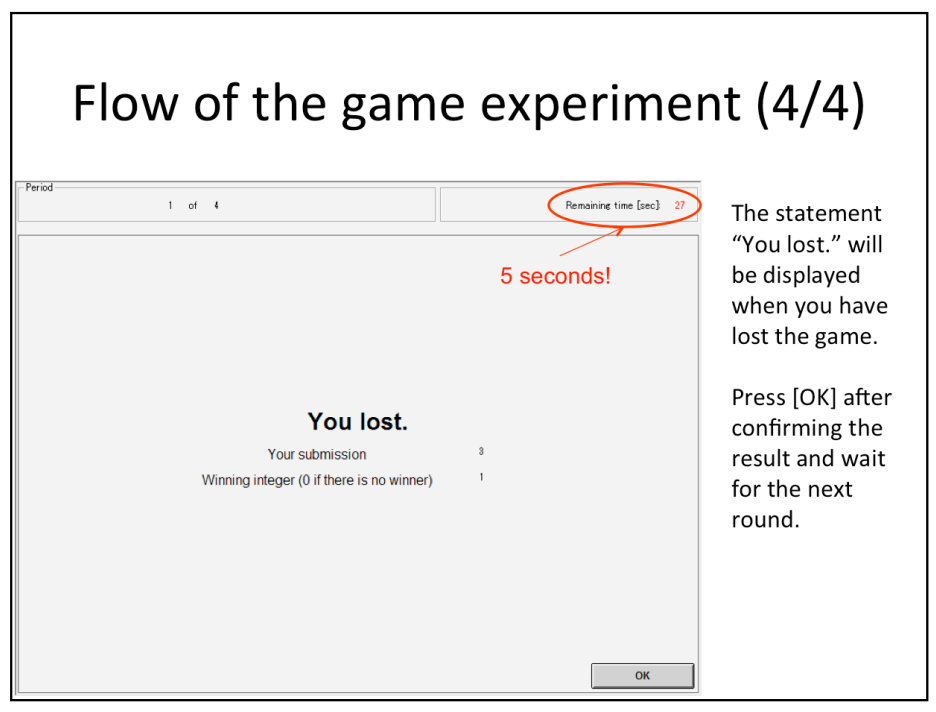

When you lose the game, the statement "You lost." will be displayed

Press [OK] after confirming the result and wait for the next round.

\section{Exercises (1/4)}

- Before starting the experiment, we would like to run an exercise.

- By doing so, you will be able to understand what today's game is all about.

- This exercise does not affect your rewards.

Before starting the experiments, we would like to run an exercise. By doing so, you will be able to understand what today's game is all about. Please note that this exercise does not affect your scores or rewards.

Go on to the next page. 


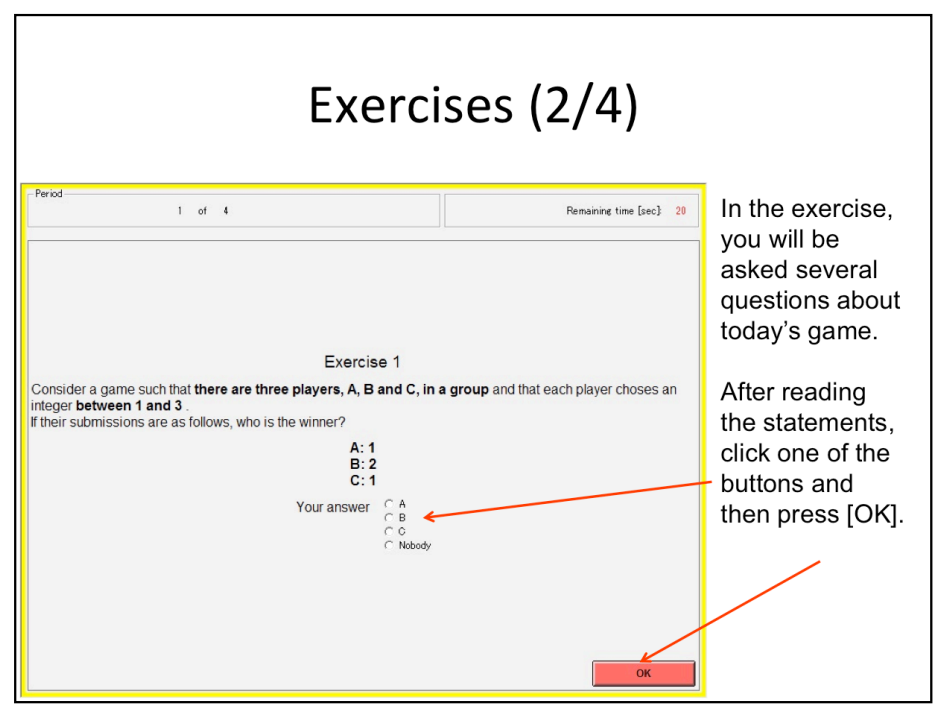

In the exercise, you will be asked several questions about today's game. After reading the statements, click one of the buttons and then press [OK].

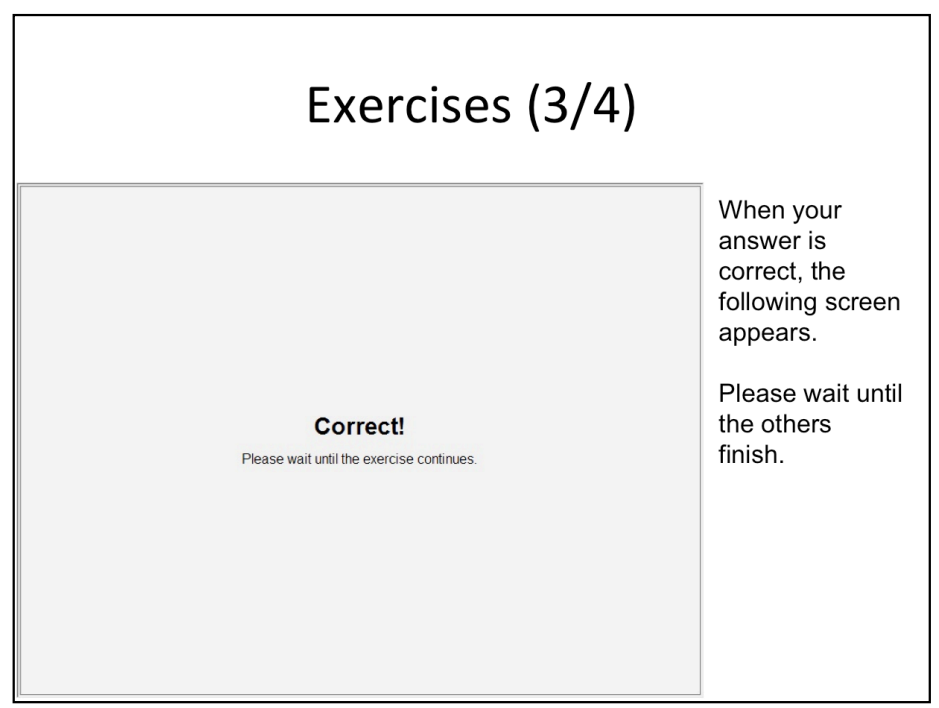

If your answer is correct, you will see the screen saying "Correct!" as the figure shows. You must wait until all of the others finish answering.

Go on to the next page. 


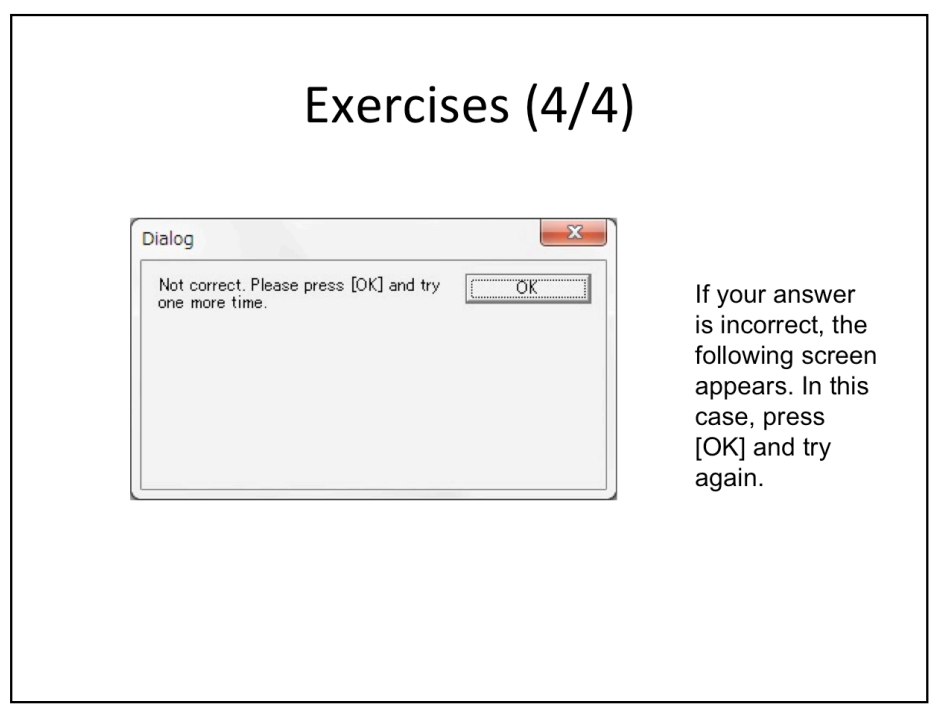

On the other hand, if your answer is incorrect, the following screen appears. In this case, please press [OK] and try again.

So, press [Continue] to start the exercise!

\section{Game 1: Start}

- Now we start Game 1. You will see the number of players in your group and the numbers you can choose from.

- When the "End of Game 1" screen appears, please wait without pressing any button.

\section{- Press [OK] to start!}

(After confirming the end of the test session.)

Now we start Game 1. Please double-click on the indicated icon on the computer screen.

You will see the number of players in your group and the numbers you can choose from.

When the "End of Game 1" screen appears, please wait without pressing any button.

Press [OK] to start]

(After Game 1) Go on to the next page. 


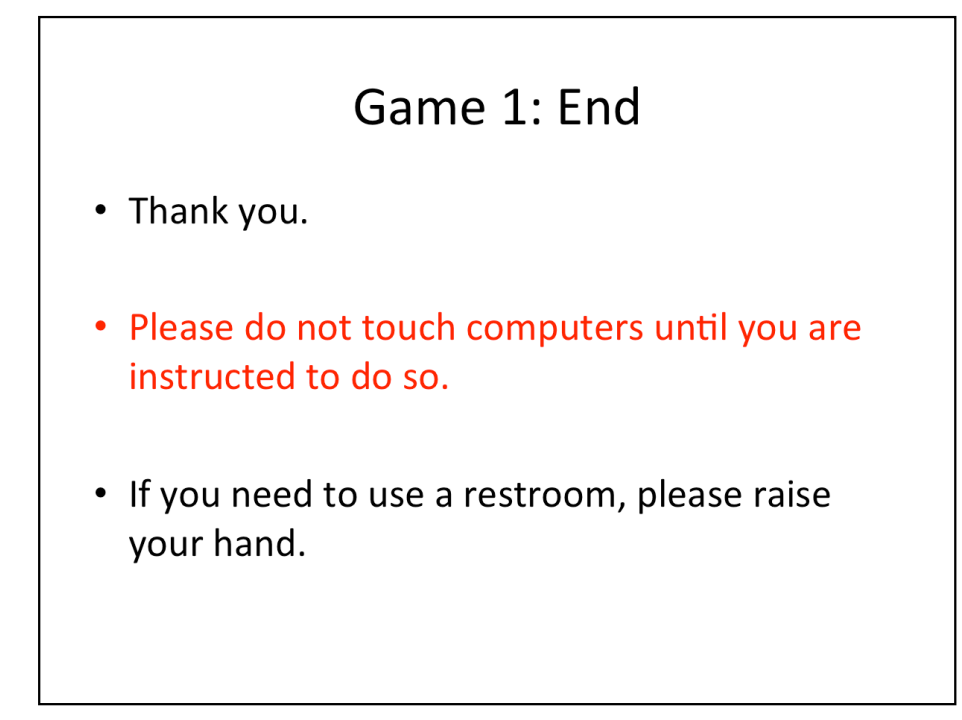

Thank you. Please do not touch computers until you are instructed to do so. If you need to use a restroom, please raise your hand.

\section{(After confirming)}

Please press [Continue].

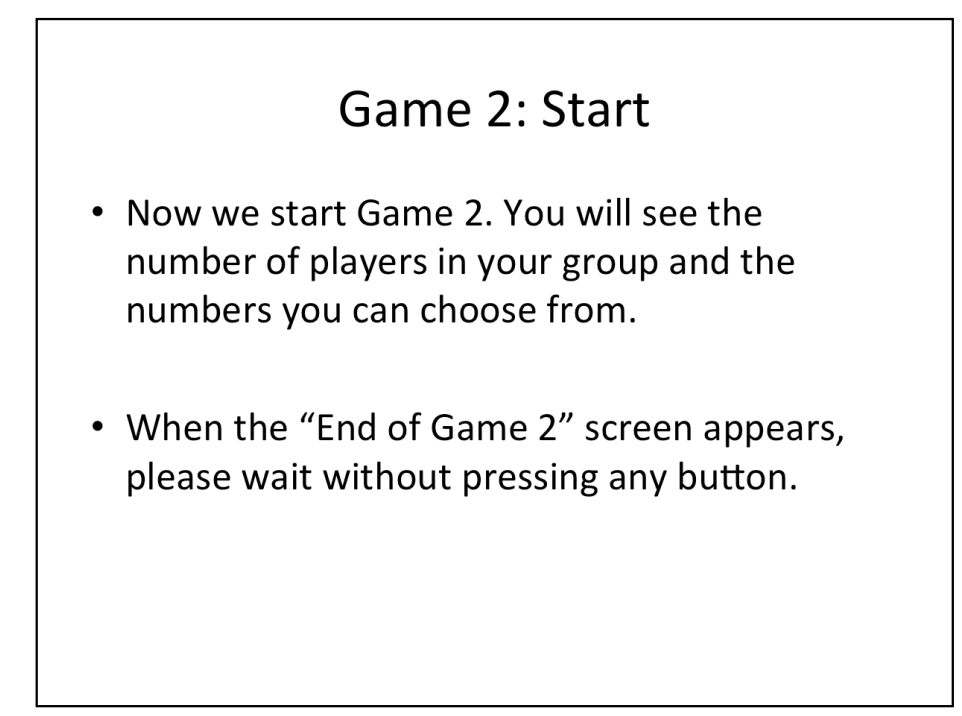

Now we start Game 2. Press [OK] to continue. You will see the number of players in your group and the numbers you can choose from.

When the screen saying "End of Game 2" appears, please wait without pressing any button.

Press [OK] to start!

(After Game 2) Go on to the next page. 


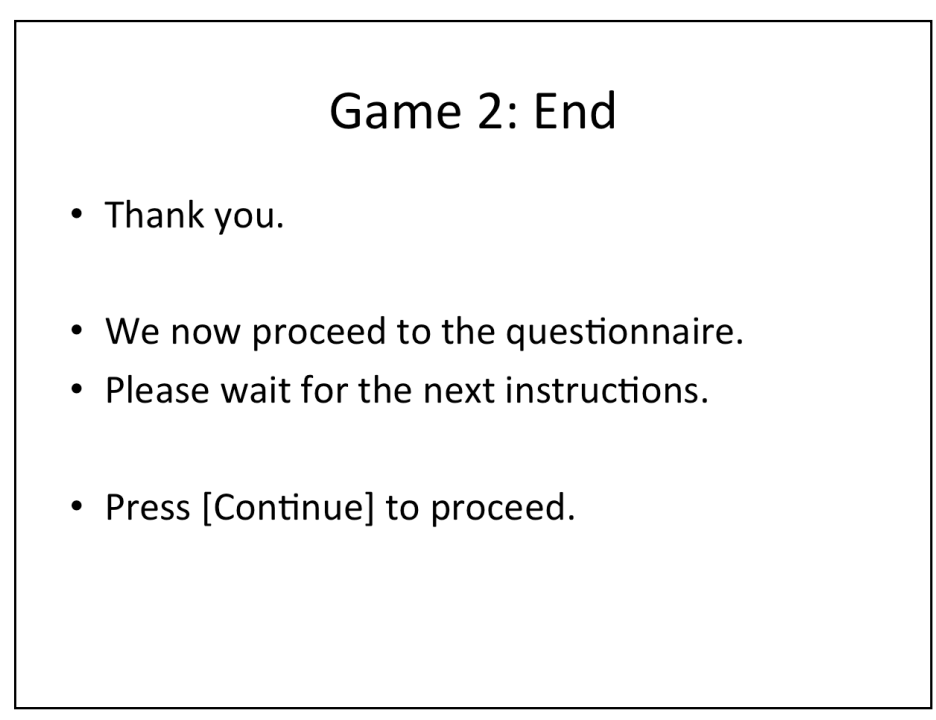

Thank you.

We now proceed to the questionnaire. Please wait for the next instructions.

Press [Continue] to proceed.

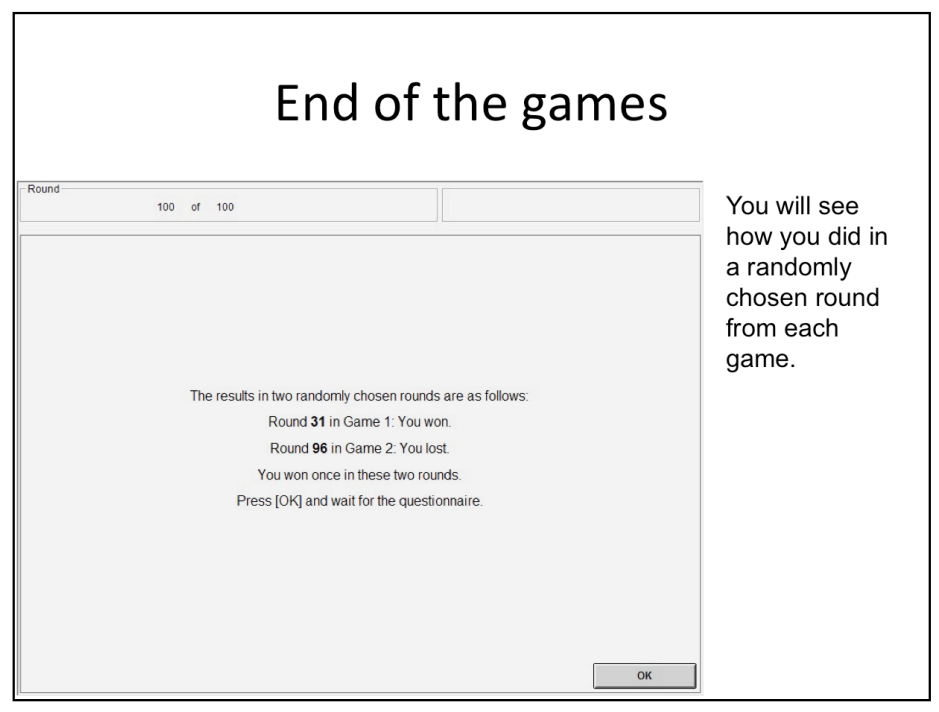

You will see how you did in a randomly chosen round from each game. 